\title{
COMPREENSÃO DE SENTIDOS ATRIBUÍDOS À AYAHUASCA: PERCURSOS TERAPÊUTICOS DO USO RITUALÍSTICO
}

\author{
Understanding of meanings attributed to ayahuasca: Therapeutic paths of ritual use
}

Comprensión de los sentidos atribuidos a la ayahuasca: recorridos terapéuticos del uso ritual

\begin{abstract}
Resumo: Ayahuasca é uma bebida psicoativa de origem amazônica preparada a partir do cipó conhecido como jagube e/ ou mariri (Banisteriopsis caapi) e do arbusto chacrona (Psychotria viridis). Seu uso cultural e ritualístico tem reconhecimento milenar por etnias indígenas da Amazônia Ocidental e ganhou influência mundial na década de 1980, por meio da expansão do seu uso religioso. No campo biomédico, estudos têm atestado a segurança na administração da bebida em humanos e encontraram características de bem-estar físico e mental em usuários. Este artigo tem como objetivo discutir os resultados de uma pesquisa que investigou histórias de vida de pessoas com itinerários terapêuticos ligados ao uso ritualístico da ayahuasca, a partir de uma compreensão fenomenológica-existencial e da gestalt-terapia. A metodologia de trabalho baseou-se na postura fenomenológica e no método de história de vida, possibilitando uma apreensão da experiência vivida nos rituais. Verificou-se, assim, que as experiências ritualísticas e os itinerários terapêuticos contribuíram no reconhecimento dos participantes de que a saúde é uma postura de maturidade ou sabedoria associada a suas relações com o mundo, atribuindo à ayahuasca a capacidade de operar ressignificações no processo cotidiano do autocuidado e, acima de tudo, no amor a si mesmos.
\end{abstract}

Palavras-chaves: ayahuasca, fenomenologia-existencial, gestalt-terapia

\begin{abstract}
Ayahuasca is a psychoactive drink of Amazonian origin prepared from vine known as jagube and/or mariri (Banisteriopsis caapi) and chacrona bush (Psychotria viridis). Its cultural and ritualistic use have been recognized from millennia by indigenous ethnic groups in the Western Amazon and gained worldwide influence in the 1980s through the expansion of it religious use. In the biomedical field, studies have attested the safety in the administration of the beverage in humans and found features of physical and mental wellbeing on users. This article aims to discuss the results of a research that investigated life histories of people with therapeutic itineraries connected to the ritualistic use of ayahuasca, from a phenomenological-existential understanding and gestalt-therapy approach. The methodology was based on a phenomenological stance and in life history method, enabling an apprehension of lived experience of the rituals. Thus, it was verified that the ritualistic experiences and the therapeutic itineraries contributed in the participants' recognition that health is a posture of maturity or wisdom associated to their relations with the world, attributing to ayahuasca the capacity to operate re-significations in the daily process of self-care and, above all, in love of oneself. Key words: ayahuasca, existential phenomenology, gestalt-therapy
\end{abstract}

Resumen: Ayahuasca es una bebida psicoactiva de origen amazónico, preparado a partir de la cepa jagube o mariri (Banisteriopsis caapi) y del arbusto chacrona (Psychotria viridis). Su uso cultural y ritual tiene reconocimiento milenario de etnias indígenas de la Amazonia occidental y ha ganado influencia mundial en la década de 1980, mediante la expansión de su uso religioso. En el campo biomédico, los estudios garantizaron seguridad en la administración de la bebida en humanos y encontraron características de bienestar mental y físico en sus usuarios. El objetivo es discutir los resultados de una investigación de la historia de vida de personas con recurridos terapéuticos de uso ritual de ayahuasca, desde una comprensión fenomenológica-existencial y de la terapia gestáltica. La metodología se basa en la actitud fenomenológica y en el método de historia de vida, lo que permite una aprehensión de la experiencia vivida. Así, se verificó que las experiencias rituales y los recurridos terapéuticos contribuyeron al reconocimiento de los participantes de que la salud es una postura de madurez o sabiduría asociada a sus relaciones con el mundo, atribuyendo a la ayahuasca la capacidad de operar resignificaciones en el proceso diario de autocuidado y, sobre todo, de amor a sí mismo.

Palabras clave: ayahuasca, fenomenología-existencial, gestalt-terapia 


\section{Introdução}

Este artigo tem como objetivo compreender as atribuições de sentido conferidas à ayahuasca na construção de percursos terapêuticos ligados ao uso ritualístico da bebida. Os resultados apresentados fazem parte de uma pesquisa de doutorado sobre histórias de vida de pessoas com itinerários terapêuticos ligados ao uso ritualístico da bebida, na perspectiva fenomenológica-existencial e da gestalt-terapia.

Entende-se que a fenomenologia-existencial e a gestalt-terapia permitem uma mediação cultural entre os sentidos de cura e terapêuticas ligados ao uso ritualístico de ayahuasca e as dimensões de cura e terapêutica na proposta tradicional do rito. Destaca-se que a ayahuasca é uma bebida psicoativa com registros de uso ritualístico por indígenas da Amazônia ocidental de pelo menos 2000 anos a.c. (Mckenna, Callaway, \& Grob, 1998). Seu preparo é realizado a partir da efusão de duas plantas, o cipó jagube e/ou mariri (Banisteriopsis caapi) e a planta chacrona (Psychotria viridis). Por sua vez, historicamente, os registros apontam que o uso da bebida possui diversas funções nos distintos grupos indígenas, assumindo papéis de remédio, diagnóstico e busca pela fonte da doença, no sistema de medicina tradicional da etnia, ou veículo de comunicação com o mundo dos mortos (Luz, 2002). Atualmente, o seu uso ganha contornos diferentes em cada região e cultura onde se consome a bebida. No Brasil, seu uso religioso é garantido pela Resolução n. 4 do Conselho Nacional de Políticas Públicas sobre Álcool e outras Drogas (CONAD) ${ }^{1}$.

As religiões ayahuasqueiras brasileiras contemplam três correntes principais: o Santo Daime, a União do Vegetal (UDV) e a Barquinha (Labate, 2004). Todas são herdeiras de um ou mais componentes do mesmo conjunto de referências religiosas e culturais, que inclui o xamanismo ameríndio, o cristianismo, as religiões afro-brasileiras, e também correntes orientais. Verifica-se o aparecimento de centros ayahuasqueiros independentes conhecidos como movimento neoayahuasqueiro e /ou neoxamânicos que não estão ligados institucionalmente a nenhuma dessas correntes religiosas, mas recebem influências semelhantes de referências religiosas, espirituais e culturais (Labate, 2004).

Por fim, o estudo de itinerários terapêuticos com uso ritualístico da ayahuasca ganha destaque por meio do aumento de estudos que demonstram o efeito benéfico da utilização da ayahuasca, no alívio do sofrimento e no bem-estar de indivíduos e grupos (Assis, 2016; Bouso \& Riba, 2014; Dias de Jesus Jú-

1 O processo de regulamentação do uso da ayahuasca no Brasil resultou na construção de uma resolução que permite o uso ritualístico da bebida. Em 2004, o Conselho Nacional Antidrogas (CONAD) promoveu uma revisão das recomendações feitas para o uso da ayahuasca e instituiu novamente um Grupo Multidisciplinar de Trabalho para levantamento e acompanhamento do uso religioso da ayahuasca, bem como para a pesquisa de sua utilização terapêutica. Os termos de regulamentação do uso da ayahuasca foram publicados no Diário Oficial da União no dia 26 de outubro de 2010. nior, de Oliveira Salvi, \& Ramos Evangelista, 2015; Doering-Silveira et al., 2005; Escobar, 2012; Grob et al., 2004; Halpern et al., 2008; Lizardo de Assis, Faria \& Lins, 2014; Mercante, 2013; Mercante, 2017; Mckenna, 2004; Osório, 2011; Osório et al., 2015; Palhano-Fontes et al., 2013; Palhano-Fontes et al., 2019; Silveira et al., 2005). Sobre as propriedades terapêuticas da bebida, seja no campo científico, espiritual ou social, trata-se de uma complexa relação epistemológica que compreende diferentes sentidos e significados sobre saúde e cura. Equacionar o fenômeno de transformação e cura vivido pelas pessoas na prática ritualística da ayahuasca, com possibilidades terapêuticas de tradição científica, é um exercício de interculturalidade complexo e difícil, em um campo onde práticas de cura já estão investidas pelas formas de medicina tradicional e alternativa que vêm sendo utilizadas pelos grupos, independentemente de sua comprovação científica.

Neste texto abordaremos a contribuição da perspectiva fenomenológica-existencial e da gestaltterapia para abordar a compreensão de cuidado e a cura em trajetórias de vida, em que os protagonistas entenderam a vivência do uso ritualístico da ayahuasca como uma oportunidade para ressignificações de sentido em suas vidas. Nesse cenário, é possível evidenciar itinerários terapêuticos para buscar alívio e transformação para o sofrimento, numa lógica de cuidado assumida pelas culturas ritualísticas como uma prática de saúde. O sentido do ser é a base da investigação fenomenológica de Heidegger (1927/2005). Em sua análise, o ser e o mundo foram interpretados de maneira indissociável, sendo o ser expresso ontologicamente enquanto ser-no-mundo, compreendido como Dasein. A partir desse traço constitutivo do ser, Heidegger entende que o homem é o único ente que pode compreender as características de seu ser-no-mundo, podendo abranger o ser em sua totalidade ou essência. Contudo, dentro dessa totalidade, o Dasein se manifesta não pela essência, mas a partir da experiência.

A essência apresenta-se enquanto um lugar de poder ser, e reconhecimento da totalidade do ser. Mas, em termos de existência, a Dasein é um ser-no-mundo e, com isso, também se apoia nesse para viver. Nesse contexto de interpretação do ser enquanto ser-no-mundo, que só pode ser apreendido enquanto experiência vivida, é que compreendemos a perspectiva concernente à experiência das pessoas que fazem uso ritualístico com ayahuasca. Tem-se a compreensão de que os efeitos dessa bebida psicoativa não podem ser dissociados da experiência do uso ritual e vice-versa, sendo impossível interpretar as qualidades da vivência apenas pelas características psicoativas da ayahuasca, assim como também não é possível compreender tal vivência apenas pelos seus efeitos simbólicos de uso ritual. Enquanto experiência do ser-no-mundo, as duas dimensões são indissociáveis. Entendemos o uso ritual, no contexto de pessoas que buscam ajuda para lidar com situações de sofrimen- 
to, como uma possibilidade de encontro com o poder ser, a partir do qual, torna-se viável a experiência do esclarecimento do ser em si e do ser com os outros, propiciando a chance de modificação na relação do ser-no-mundo.

Para compreender o fenômeno, trataremos também do sentido de cuidado e cura. Sorge, conceito trabalhado por Heidegger (1927/2005), significa cuidado e também pode ser traduzido como cura. Isso porque, enquanto ser-no-mundo, o Dasein assume no cuidado a possibilidade de conhecimento de si. Nessa perspectiva, o cuidado passa a ter ação fundamental enquanto possibilidade de esclarecimento do ser, gerando também a possibilidade de o poder ser em liberdade.

Heidegger (1927/2005) discute o conceito de cuidado como ocupação e preocupação. Assim, em sua relação com o mundo, o ser humano ocupa-se dos entes e os cuida à medida em que os insere em seu projeto existencial. Mas, enquanto ser-no-mundo, o ser humano também vive com outros seres-no-mundo. Nesse caso, constrói-se enquanto um ser junto ao mundo, no qual se preocupa com os outros. Assim, o cuidado toma a dimensão de solicitude ou preocupação. Em ambos os casos, o cuidado atualiza as possibilidades do ser-nO-mundo enquanto um poder ser com maior liberdade e presença.

Portanto, o cuidado pode ser interpretado como o próprio ser-no-mundo e podemos compreender que nessa ação fundamenta-se a própria ideia de um poder ser na propriedade da presença ou na potência originária, que se é desde sempre, já que o ser é lançado no mundo desde o início da sua existência. Seguindo essa reflexão, o ser-no-mundo pode se abrir para experimentar o presente, decidindo livremente em meio às possibilidades que se apresentam, entre a propriedade e impropriedade da presença. Destarte, o poder ser em presença diante de si mesmo pode ser interpretado como cura.

Para Heidegger (1927/2005), o sofrimento nasce da privação do Dasein e da falta da possibilidade de uma escolha autêntica de viver. Por sua vez, o cuidado é a própria condição do ser-no-mundo que carece de ajuda para alcançar a realização de si mesmo. Essas noções de sofrimento e cuidado no contexto da fenomenologia-existencial são compartilhadas em gestalt-terapia, que entende o ser e o mundo em continua relação. Assim, Perls (1973/1988) apresenta a ideia de mente e corpo como aspectos diferentes e complementares da existência, não podendo ser analisados separadamente. A mesma relação é válida para o organismo e o meio: sendo o organismo ou homem a unidade dentro de uma totalidade do ser e meio, e o mundo, lugar onde se dão as relações do ser.

Uma pessoa existe em sua totalidade e sua existência só se torna compreensível num determinado campo em que ela se encontra em relação. Essa abordagem considera a pessoa uma função do campo, composto pelo organismo, meio e comportamento (Perls, 1973/1988). O ser humano recorre a duas funções que permitem a estabilidade do organismo-meio: o auto-apoio e a auto-regulação. No processo de auto-regulação, o organismo busca satisfazer suas necessidades de modo mais pleno possível, visando à manutenção do equilíbrio ou do estado saudável. Já o auto-apoio é um recurso do organismo no qual a pessoa consegue mobilizar recursos próprios na busca do equilíbrio.

Na pessoa saudável, essas funções trabalham de forma a ajustar as relações do organismo com o meio, em uma apropriação autêntica de aceitação de si e do outro. Em oposição a esse comportamento maduro, favorável à flexibilidade e criatividade nas relações, uma pessoa adoece à medida em que perde a capacidade de autorregular suas relações com o meio, atuando de forma rígida e desequilibrada socialmente. Perls (1973/1988) destaca que a pessoa perde a capacidade de se auto-apoiar e passa a depender do apoio ambiental para se realizar, gerando desequilíbrio e adoecimento pela cristalização de atitudes dissonantes do organismo, ou seja, as relações do organismo podem variar entre ações de estar com o mundo ou estar no mundo. Em suma, as relações com o mundo permitem flexibilidade e criatividade do ser, evidenciando um organismo auto-regulado e auto-apoiado. As relações no mundo são relações enrijecidas que se caracterizam pela anulação do organismo diante do meio e que podem caracterizar processos de sofrimento e desequilíbrio.

Perls (1973/1988) define a saúde e a maturidade psicológica como a capacidade de o organismo emergir do apoio e da regulação ambiental para um auto-apoio e uma auto-regulação. O dilema entre agir conforme suas necessidades e as do meio são base para a saúde e maturidade psicológica. O processo de sofrimento nasce de um comportamento de fuga pela dificuldade de regular as necessidades do organismo e o meio. Atuando exclusivamente pelo apoio e regulação do meio, a pessoa perde a capacidade de se conhecer, de se reconhecer e deixa de aceitar a si mesmo, em razão de uma aceitação do meio. A fuga, submissão e aceitação passiva das ordens e das ações impostas pelo meio, sem contestação ou questionamentos, são tipos de introjeção, que por sua vez, geram conflitos de não aceitação, afirma Perls (1973/1988). Quando em conflito, o organismo perde a capacidade de dar respostas criativas, limitando-se a viver em ritmo de contato e fuga, e adoece. O processo de crescimento psicológico, diferentemente disso, é um processo de conscientização dessa dinâmica, em direção à natureza auto-reguladora do organismo humano, que se percebe dentro desse ritmo.

\section{Método}

Este estudo foi baseado no método de história de vida oriundo da psicossociologia (Gaulejac, 2014) e na compreensão fenomenológica existencial pro- 
posta por Heidegger (1927/2005) e da gestalt-terapia proposta por Perls (1973/1988). A pesquisa retrata o universo da experiência vivida pelos participantes no ritual com ayahuasca em sua relação com seus percursos de vida. A história de vida da pessoa, no que diz respeito à manifestação de sua existência, revela narrativas mais complexas sobre aspectos históricos, sociais e pessoais, base para a escolha de itinerários terapêuticos diante do sofrimento. Esse enfoque considera que cada pessoa traz ao campo relacional uma narrativa de si mesmo. Ser narrador de si mesmo é, antes de tudo, poder se conhecer, apropriando-se de sua existência, que se faz dentro de uma temporalidade e historicidade (Critelli, 2012). Assim, na construção dessa narrativa sobre si, nasce a possibilidade do coexistir dessa história no campo relacional, podendo exigir uma escuta que se vincule e que se aproprie dessa história, dando chance a que ela exista nas relações com o mundo.

Neste estudo serão apresentados os casos de duas pessoas com experiências pregressas de sofrimento associado ao uso de álcool e outras drogas e histórico de participação em rituais de ayahuasca e cujos nomes aqui adotados são fictícios. O projeto foi considerado adequado às exigências da Resolução CNS 466/2012 e complementares e aprovado pelo comitê de Ética em Pesquisa do Instituto de Ciências Humanas da Universidade de Brasília ( $\mathrm{n}^{\circ} 53540316.4 .0000 .5540$ ). Para a escolha dos participantes priorizou-se o registro de sofrimento psíquico em suas histórias, destacando, em especial, aqueles associados ao uso de álcool e outras drogas. Os participantes foram contatados em vários centros ayahuasqueiros. Para registro de suas biografias, foram realizados encontros individuais com cada um deles. Todos os encontros foram gravados e também registrados por meio de anotações. A condução das entrevistas foi livre, na qual apenas se solicitou que narrassem, desde o seu nascimento, questões que consideravam importantes em suas vidas. Não foi realizada nenhuma pergunta diretamente relacionada ao contexto da ayahuasca, deixando essa dimensão aparecer espontaneamente nos relatos. Ao final das entrevistas, pedia-se a cada participante que narrasse sua concepção sobre cuidado e saúde. Os registros das histórias foram gravados em áudios para posterior construção das narrativas. Concluídas as narrativas das histórias, os participantes foram contatados novamente para ler, opinar e modificar o registro final de seus relatos.

A análise de cada narrativa revelou a necessidade de leituras diversas das histórias de vida, o que possibilitou a identificação de unidades de significado importantes à compreensão de sentidos conferidos à ayahuasca na construção de percursos terapêuticos ligados ao seu uso ritualístico. Os participantes narraram suas experiências a partir de relatos sobre vivências de crescer, se divertir, sofrer e se equilibrar. Esses foram os sentidos captados inicialmente, que utilizamos para analisar os processos de escolha de um percurso terapêutico e as tentativas de reequilibrar a saúde. A análise possibilitou uma apreensão da experiência vivida dos participantes que resultou em seis unidades significativas: o reconhecimento de um sofrimento; a busca de bem-estar; o encontro com as drogas; o encontro com a ayahuasca; a ressignificação de sentidos; e, o encontro com o sagrado. Para ilustrar a compreensão fenomenológica na construção de percursos terapêuticos ligados a ayahuasca, serão apresentados a seguir a história de vida de dois desses participantes, assim como o processo de discussão categorizado na pesquisa.

\section{Resultados}

Paulo: questionador, polêmico, mas com sensibilidade

Paulo é um jovem de 24 anos, homossexual, solteiro, produtor de eventos, que gosta de curtir a vida com “ousadia e emoção". Sua história representa a luta de milhares de pessoas que não são aceitas pela sociedade e que vivem a dificuldade de serem diferentes da norma social. A vida de Paulo é uma denúncia social, de preconceito, discriminação e do sofrimento que o modelo em que vivemos pode ser capaz de provocar.

Paulo se define como uma "criança precoce" que já gostava de política aos 11 anos de idade e não conseguia entender algumas contradições da sociedade. Originário de família de classe média com tradições patriarcais bem definidas, Paulo define o pai como autoritário, situação que lhe causou muitos conflitos na adolescência quando o jovem se descobre homossexual. Na época, aos 15 anos, foi levado ao psiquiatra e ao psicólogo e foi diagnosticado com Transtorno de Déficit de Atenção e Hiperatividade. Para Paulo, o diagnóstico foi uma saída da família aliada aos profissionais de saúde de ignorar a sua orientação sexual. Refere-se a essa época como de muitas brigas familiares, violência e apatia intensificada pelo uso de remédios psiquiátricos. Entre os 15 e 18 anos, a vida adulta se aflorou, "com muita rebeldia e transgressão". Acha que perdeu "muita coisa nessa época”. Era "uma pessoa sensível e carinhosa" e teve que "endurecer para enfrentar o preconceito e a discriminação”. Terminou o ensino médio aos 18 anos e decidiu que não faria faculdade. Decidiu trabalhar como produtor musical e conseguiu certa estabilidade financeira na vida. Paulo "ganhava muito dinheiro, de dois a três mil reais por semana”. E “fazia muita farra”. "Dava uísque para todo mundo, alugava quarto de hotel”, entre outros programas. Hoje ele entende que "era um mecanismo burro e infantil que encontrou de ser aceito". Por trás do adolescente engajado e ousado, existia o adolescente sensível que ainda lutava por aceitação. "O grande ponto dentro de tudo isso era ser aceito naquele lugar, então queria alimentar aquele lugar cada vez mais para que ele nunca morresse”. Sabe que sofreu muito e encontrou "refúgio no meio de pessoas muito 
rebeldes e transgressoras". No fundo, não se "sentia um transgressor, só precisava parecer um”. Nesse sentido, considera que a estrutura social que lhe acolheu contribuiu muito para sua "relação com as drogas". Usa cocaína até hoje, mas não acha que "é um vício". Não acorda e precisa cheirar cocaína e não sabe o que é "abstinência”. Se tem uma droga de que se considera "dependente, essa droga é a maconha". Sente "vontade de fumar todos os dias para ficar relaxado, para controlar um pouco a ansiedade".

Segundo Paulo, o encontro com o uso ritualístico da ayahuasca trouxe um aprendizado sobre ele mesmo que lhe permite ter mais consciência sobre seus hábitos e comportamentos, entender melhor seus sentimentos e ressignificar histórias e sentidos na sua vida. O "olhar para dentro" lhe permitiu acessar seu sentimento de culpa em relação ao seu estilo de vida, seu sentimento de raiva em relação à sociedade e família, e sua necessidade de mudança no padrão de uso de drogas para sentimentos de amor à família e aos amigos, além de conseguir se aceitar: "Eu me aceitei”, diz. Mas, em alguns momentos da vida, Paulo sedimentou os sentimentos. Esqueceu-se da sua essência que é o amor, ele diz. "Ayahuasca me permitiu estar em contato de novo com essa essência”.

Paulo sente que amadureceu. Não abriu mão do seu estilo de vida, mas sente que não lhe preenche mais. Faz algumas análises sobre envelhecimento: "não vou poder viver assim para sempre". Hoje procura ser menos impositivo nas relações e compartilhar mais do ponto de vista dos outros. É como se o chá lhe permitisse entrar em contato com outros valores que são considerados importantes hoje, mas que também fazem parte de um processo de amadurecimento. Com relação ao seu estilo de vida, frisa em especial o seu ressignificado na relação com as drogas: "O chá me permitia estar em contato com as drogas e entendê-las como parte desse mundo, da minha vida, da forma como eu vivo, do meu estilo de vida, que eu tenho direito de escolher, porque eu nunca senti que as drogas também me atrapalharam”. Por outro lado, conta que o chá o ajudou a fazer um uso mais racional das drogas: "uso duas vezes por semana, pouco, bem menos do que eu já usei. Antes passava a madrugada com a cara no prato, hoje em dia fumo um baseado e deixo o povo cheirando, depois eu cheiro de novo. Parece que tenho um pouco mais de consciência. Ayahuasca me ajudou a ter essa consciência. Os trabalhos de ayahuasca me ajudaram muito a ter essa consciência. Nunca me senti culpado, eu me senti irresponsável, ayahuasca me ensinou sobre a liberdade e sobre compulsão".

Das diversas dimensões em que Paulo mergulhou em seus processos com a ayahuasca, parece que seu encontro com o uso ritualístico da bebida lhe proporcionou muitos significados para como ele atuava nas relações, permitindo-lhe conversas íntimas consigo mesmo sobre os processos de raiva e culpa que lhe impedem de se relacionar como ele gostaria. $\mathrm{O}$ chá o colocou em contato com valores que estavam adormecidos, ou "sedimentados". Em certa medida, seu estilo de vida, e em especial, sua relação com as drogas, o ajudam a elaborar esses sentimentos. Consciente desses mecanismos inconscientes que geram dor e angústia, e do amor que sente pelas pessoas, foi possível para Paulo encontrar espaço para mudança de hábitos. Dentro de sua história, objetivamente, ele coloca: "hoje é possível morar novamente com minha família, o que não era uma possibilidade pelas brigas e discussões. Hoje também é possível fazer um uso mais racional das drogas, e entender que meu estilo de vida não me sustenta mais”.

\section{Arthur: triste, para a vida, mas com consciência}

Esta é uma história de amor e ódio que, sobretudo revela a potência transformadora de conhecer-se a si mesmo. Arthur é um jovem de 25 anos que não tem muitas lembranças de si que não envolvam sofrimento, dor ou tristeza, mas que depois de muitos transtornos e perturbações, consegue manter a calma diante da vida. Professor de inglês assistente na educação infantil, Arthur é solteiro, mora sozinho, possui ensino superior incompleto e renda média de $\mathrm{R} \$ 2.000,00$. Filho não desejado de uma relação extraconjugal, a vida de Arthur é marcada por conflitos com o pai, diagnóstico de depressão infantil aos 10 anos de idade, uso e tráfico de drogas. Sua convivência com o pai só se deu a partir dos 8 anos, idade também das primeiras lembranças de Arthur. Não guarda em sua memória nenhuma cena, imagem ou sentimento mais importante até essa etapa da vida. Fora a irmã e a mãe, Arthur cresceu em meio aos primos e aos avós maternos. Com a família do pai teve pouco contato, apenas em comemorações. Arthur morou em algumas cidades antes de ir morar fora do Brasil, aos 10 anos de idade.

Arthur era uma criança sozinha. Esse isolamento chamou a atenção da escola e de sua família. Sua mãe achava que "tinha síndrome de Asperger". Os professores queixavam-se do comportamento de Arthur, e então, sua mãe tomou a decisão de levá-lo ao psiquiatra. Aos 10 anos de idade, Arthur recebeu o diagnóstico de “depressão infantil”. Assim refere: "daquele momento em diante eu nunca mais fui feliz". "Quando uma criança escuta algo assim da boca de uma pessoa respeitável, um médico ou da sua mãe, marca muito". Recorda-se que "não sabia o que queria dizer isso na verdade", mas aos poucos foi "entendendo que era doente”. O diagnóstico pesou na vida de Arthur. Dali em diante, ele conta que suas escolhas só confirmaram que era uma pessoa "triste e esquisita". No exterior, teve sua vida marcada pela depressão, pelas sessões de psicoterapia e por poucas amizades. Frequentava a escola e passava férias com pai.

Aos 15 anos regressou ao Brasil, emancipado, indo morar na casa de um primo traficante de dro- 
gas. Dos 15 aos 18 anos, as drogas fizeram parte cotidianamente da vida de Arthur, lhe trazendo muitos prazeres, mas também muitos problemas. Não tinha mais dificuldade para "ter amigos", "saía com mulheres mais velhas”, "viajava”, "participava de vários shows", mas nunca deixou de se "sentir triste". Quando voltou ao Brasil, se "sentia um lixo”. "Drogas e brigas" eram seu cotidiano. "Tinha uma ganguezinha”, "uma galerinha que saía e quebrava os lugares, pinchava muros e roubava". Começou a "usar cocaína nessa época”. Sobre esse momento de sua vida, Arthur reconhece que "era um moleque bem confuso”, "não sabia quem era”. A adolescência batia à porta e ele "não conseguia lidar com a intensidade das mudanças". Hoje ele sabe que é "bissexual”, gosta e aceita bem isso. Mas naquela época, não conseguia entender. Sabia que "era ansioso, um pouco depressivo, que não gostava de estar com pessoas, que era sentimental e não conseguia aguentar a intensidade dos sentimentos" e teve muitos problemas com isso.

Relata que machucou "muita gente". Não chegou "a matar ninguém, mas quase”. "Tem muita gente que passa pela cocaína, cheira, gasta dinheiro e tal e acabou". Agora, com ele "foi pesado", reflete. Entrou naquele mundo de verdade, "vendia quilos e quilos". "Mexia com o comércio. É um negócio, mas também queria usar". "Não tem outra palavra para descrever, é uma treta constante, você acorda nela e vai dormir nela, porque tem dinheiro envolvido e é uma coisa proibida”. "O pó é a droga do super-homem”. "Você fica feliz, se sentindo bem, se sentindo poderoso. Você pode fazer tudo que você quiser". "A onda do pó é você querer sempre mais". E era esse poder, esse sentimento de fazer tudo o que quisesse que dava a coragem para Arthur entrar na casa das pessoas e cobrar a dívida, da forma que era necessário fazer, com intimidação e violência. Sabe que se tornou "dependente", "não conseguia passar três dias que fossem sem cheirar”. A cocaína era uma forma de deixar de sentir. "É na verdade a droga para engarrafar os sentimentos".

O conflito de consciência sempre esteve no cerne dos sentimentos de Arthur, ou seja, a impulsividade lhe fazia agressivo, mas logo depois, mergulhava num sentimento de tristeza profunda pelo teor da violência de seus atos. E, dessa forma, a depressão nunca deixou de fazer parte do seu cotidiano. Procurou "por conta própria”, uma psiquiatra assim que regressou ao Brasil. Mas novamente, não se sentiu compreendido. Na primeira consulta, confirmou o diagnóstico de depressão. Episódios de autoagressão, heteroagressão e uma tentativa de suicídio, fizeram parte de sua história clínica. Fazia consultas regulares de dois em dois meses e usava a medicação. Seguia a receita à risca porque "quando ficava sem os remédios”, se "sentia pior". Grande parte da sua "vida terapêutica foi essa de chegar no escritório da psiquiatra e pegar a receita”. "Teve uma época que a consulta demorava, não mais que cinco minutos”.
O encontro de Arthur com ayahuasca deu-se quando ele tinha 23 anos, a convite de um amigo. Avalia que esse encontro lhe permitiu uma ressignificação ampla e feliz de muitos processos em sua vida: suas relações afetivas; sua forma de lidar com as pessoas; a violência praticada contra si e contra os outros; a relação com as drogas e a dependência física e psicológica da cocaína; sua forma de lidar consigo mesmo, com a ansiedade, e suas questões existenciais que eclodiram durante seu processo de depressão. Ele considera que seus trabalhos com a ayahuasca lhe permitiram uma nova visão de sentidos para a vida, que pode ser sintetizada na seguinte frase: "hoje em dia, eu tento me redefinir todos os dias, é isso". "A ayahuasca me possibilitou um sentimento de autoperdão, de aceitação da minha condição", diz ele. "De aceitar que eu gosto de homens também. Aceitar de verdade, não só me divertir e depois negar. De aceitar que minha sexualidade é assim. De aceitar que estou longe da minha mãe. São coisas que mexem com meu interior e coisas com as quais eu tinha conflito".

A partir do autoconhecimento e da aceitação de si mesmo, Arthur pôde se abrir para sentidos que estavam encobertos, e as transformações vieram, dentre elas, a mudança de sua postura em relação às drogas, especialmente a cocaína. "Foi algo que me transformou de verdade. Depois do primeiro trabalho, eu percebi que nunca mais eu ia usar cocaína na minha vida”. Arthur não voltou mais ao psiquiatra e parou de usar a medicação. Comenta que deixou de frequentar o grupo ayahuasqueiro, mas que as mudanças permanecem em sua vida. No mais, comenta suas reflexões, todas em âmbito de uma consciência profunda sobre si mesmo e de como se relacionava com as pessoas, seu envolvimento com o mundo das drogas e do tráfico. "A ayahuasca ajudou a me perdoar, dizendo que eu fiz isso, mas não vou fazer mais. Acabou, mas para mim foi uma coisa muito feia mesmo". Objetivamente, Arthur conseguiu sentir mais respeito e ter mais empatia nas relações afetivas e parar de traficar e usar cocaína, que era um motor para cometer atos de violência. Porém, Arthur não se sente curado. Acha que vai lutar com processo de dependência da cocaína durante toda a vida. Ainda tem muitos pensamentos obsessivos, que lhe questionam sobre o significado da vida e o porquê fazer parte disso tudo. Sente, às vezes, que nada faz sentido, e isso lhe confronta com pensamentos suicidas. Ademais, ainda se crê egoísta nas relações. O processo de autoconhecimento aliado ao amor e a compreensão emergentes dessa conscientização, integram o processo de transformação de Arthur. Assim diz: "muito amor, só amor. Amor próprio, amor pelas pessoas da minha família. Eu percebi que eu estava escondendo esse amor, que eu não estava aceitando ele, e que esse amor seria capaz de melhorar tudo em mim, se eu deixasse ele fluir”.

Ayahuasca e as drogas: A redução de danos de Paulo e a abstinência de Arthur 
O tema ayahuasca e drogas merece um destaque especial por suas múltiplas significações no campo de estudo da drogadição. $\mathrm{O}$ encontro com as drogas foi uma unidade significativa bem enfatizada na narrativa de Arthur e Paulo, tanto pelo lugar que as drogas tiveram ou têm na vida, quanto pela contraposição do uso de drogas ao uso da ayahuasca. Guardadas as devidas idiossincrasias, o encontro com as drogas foi parte importante de suas vidas. O uso da ayahuasca, por sua vez, representa uma possibilidade de autoconhecimento, e ganha destaque em suas narrativas de vida.

Paulo revela que seu envolvimento com as drogas estava ligado à necessidade de viver uma rebeldia associada à transgressão das normas sociais. Para ele, esse encontro representou uma forma de se relacionar com um grupo que se define pela transgressão. Paulo destaca que a relação com as drogas o afastou de si mesmo e o ajudou a criar um personagem para ser aceito no grupo social. Arthur vê no encontro uma possibilidade de se relacionar com o mundo, questão que lhe era bem conturbada. Contudo, acha que essa relação também se tornou agressiva e prejudicial aos seus relacionamentos e a si mesmo.

Paulo e Arthur, ademais, ressaltam a capacidade, especialmente da cocaína, de lhes conferir uma sensação de poder. Ainda que contraditoriamente, indicam no uso de drogas uma busca para sentir-se bem. Diante das dificuldades e sofrimentos enfrentados de forma particular em cada uma das histórias, a droga é consequência do contexto relacional e das necessidades de busca de cada um. O envolvimento que cada um faz com as drogas, os riscos e os danos, fazem parte de uma trajetória singular de vida. Refletindo o uso de drogas a partir desse contexto, ressalta-se que o fenômeno da drogadição não se reduz a uma relação linear de causa e efeito, mas insere-se numa perspectiva complexa, envolvendo diversas variáveis interatuantes. Porém, raramente o fenômeno é considerado em sua amplitude e complexidade, sendo estudado a partir das relações de violência e do tráfico ou da perspectiva de tratamento para os dependentes (Assis et al., 2013).

Nesse sentido, buscando uma melhor compreensão sobre o fenômeno do uso de drogas, voltamos a nossa atenção para a ayahausca. A ayahuasca é uma bebida psicoativa, cujo uso ritualístico difere completamente da forma como se vive a relação com os demais psicoativos denominados de drogas. Ambos os participantes vivem a prática ritualística como uma forma de ajuda para um sofrimento vivido. Antes da sua inserção no ritual, identificavam a ayahuasca como uma bebida alucinógena. Imaginavam propriedades e efeitos semelhantes àqueles que já tinham vivenciado quando usaram LSD. Assim, para eles, beber ayahuasca também era representado pelo medo das alucinações e da loucura.

A relação entre ayahuasca e droga foi completamente desfeita por eles no primeiro contato com o uso ritualístico com a bebida. O uso de drogas foi mo- tivado por situações de rebeldia, transgressão, busca do prazer, aceitação em um grupo social, satisfação de necessidades básicas, além de busca de euforia, redução da ansiedade e impulso para realização de ações proibidas e/ou prejudiciais a si mesmo e aos outros. O uso da ayahuasca é motivado pela busca de cuidado, conhecimento de si e encontro com o sagrado, além de vínculos empáticos. Para Bucher (1996), uma substância psicoativa só se torna uma droga dentro de um determinado contexto de relações entre atividades simbólicas e ambientais. Já dizia Olievenstein (1989), que a drogadição é uma equação que envolve um produto, uma personalidade e um momento sociocultural. Ambos compreendem o uso de drogas como um fenômeno complexo que envolve multifatores.

Analisando por esse ângulo, e entendendo que as inspirações pessoais, sociais, culturais e espirituais para o uso da ayahuasca são completamente diferentes daquelas que motivam o uso de drogas, é importante não só diferenciar esses contextos, mas também avaliar com cuidado a classificação da ayahuasca dentro das categorias de estudo da drogadição. Ainda que para algumas pessoas o uso ritualístico da bebida possa inspirar a abertura para a vivência de uma cultura psicoativa, a tradição ayahuasqueira, em seus mais variados segmentos, representa a bebida como sacramento, veículo de concentração mental, medicina, contato com o mundo espiritual, entre outros significados, dimensões que oferecem suporte para a regulamentação do uso ritualístico da ayahuasca no Brasil.

A história de Paulo nos traz contribuições importantes para o estudo desse fenômeno, porque nos evidencia que a relação entre o uso da ayahuasca e a interrupção do uso de drogas não é direita. Também nos ajuda a contestar interpretações simplistas de que o uso da ayahuasca por si só gera um efeito de abstinência. Na clínica do cuidado a usuários de drogas, a relação de abstinência pode ser almejada, sendo inclusive, base para as experiências de tratamento da dependência química com o uso da ayahuasca (Mercante, 2013).

Contudo, a narrativa de Paulo evidencia que existe uma questão relacional importante: querer usar ou parar de usar drogas. E que diante de uma indisponibilidade para parar o uso, é possível fazê-lo de forma não prejudicial. Paulo reflete que é possível conviver com o uso de drogas, ter prazer e, ainda assim, se cuidar. A experiência de conhecimento de si com a ayahuasca lhe confirma essa possibilidade enquanto direito que ele tem de consumir drogas. Paulo traz em sua narrativa o uso ritualístico da ayahuasca como uma experiência de redução de danos. Nos estudos sobre a clínica do uso de drogas, esse é um fenômeno bastante em evidência e surge como uma iniciativa ética também no cuidado profissional aos usuários de drogas por setores da saúde. Essa perspectiva, reconhece cada usuário em 
sua singularidade, traçando com ele estratégias que estão voltadas não para a abstinência como meta, mas para a melhora da qualidade de vida (Assis et al., 2013). Os princípios associados ao tratamento com redução de danos objetivam, em primeiro lugar, o alcance de uma melhor qualidade de vida do usuário, e assim, Paulo entende seu encontro com a ayahuasca. A redução de danos como ética do cuidado não se prende ao consumo da droga, mas se articula aos aspectos emocionais e sociais, à forma de se relacionar que a pessoa tem, em função do uso de drogas.

Para Arthur, a experiência de conhecimento de si deu-lhe uma chance para a abstinência imediata do uso de cocaína. Arthur, após um ano, deixou de frequentar a prática ritualística, e entende que viveu um processo de cura de dependência de cocaína. Dentro desses aspectos, este estudo alia-se a outros estudos que têm apontado o uso da ayahuasca como uma possibilidade de cuidado no contexto de uso abusivo de drogas. Como essa ação de cuidado é interpretada é que, essencialmente, precisamos refletir. Trata-se de uma ação de substituição de uma droga por outra droga, como alternativa para diminuir riscos e danos, consolidando-se como proposta de redução de danos, mas que qualifica a ayahuasca fora de seu contexto ritualístico? Trata-se de substâncias com propriedades anti-dependência e com potenciais de desenvolvimento de novos fármacos que poderão, mediante a comprovação de sua eficácia, ser administrados de forma prescrita? Ou trata-se de um saber tradicional, devendo ser incorporado em estudos e aplicabilidades, a partir de seus contextos, conhecimentos e técnicas, ampliando a noção reducionista do paradigma científico sobre saúde?

\section{Discussão}

O percurso terapêutico dentro do uso ritualístico da ayahuasca

De modo geral, as duas histórias apresentam motivações e itinerários singulares na participação em prática ritualística, evidenciando processos de sofrimento ou desenvolvimento de enfermidades no campo da saúde mental e também um percurso na busca de soluções e de bem-estar. As duas histórias apresentam em comum, além do encontro com ayahuasca, trajetórias de vida marcadas pelo encontro com as drogas e com a transgressão, aspectos também relevantes na análise do sofrimento. Na concepção dos participantes, o encontro com a ayahuasca surge como uma possibilidade de cuidado e conhecimento de si, que permite uma ressignificação de sentidos e projeta uma melhor qualidade de vida. A potência desse encontro na transformação de sentidos se manifesta na tomada de consciência de aspectos renunciados ao ser, mas, em especial, no encontro com uma força abstrata e não racional, que se manifesta como um fenômeno sagrado.

Em relação ao sofrimento, ambos os participantes revelam processos de enfermidade, aflição e angústias dentro de suas relações com o mundo (Heidegger, 1927/2005). Arthur apresenta um diagnóstico médico de depressão e apresenta uma noção de sofrimento definida pela doença, em oposição a sua experiência. Paulo, por sua vez, nunca concordou com o diagnóstico de Transtorno do Déficit de Atenção e Hiperatividade (TDH) apresentado a ele quando adolescente, reconhecendo o sofrimento na angústia e ansiedade manifestadas nas suas relações afetivas e sociais.

Ambos explanam as dificuldades que lhe foram impostas a partir do diagnóstico que os fez preponderar a doença ante suas histórias de vida e sofrimentos marcantes, e que, em determinados momentos, ajudou a construir uma relação disfuncional com o mundo. Essas situações, por sua vez, foram determinantes para se reconhecerem como pessoas em sofrimento e se imbuírem de perspectivas de mudança, na busca do bem-estar.

A história de vida de Arthur foi marcada pelo sentimento de tristeza e pela dificuldade de conferir sentido à vida. Faz parte de sua história de sofrimento, além do diagnóstico de depressão e de um quadro clínico associado ao uso de drogas, a dificuldade de estabelecer contato com as pessoas e de construir relações saudáveis, pautadas na não violência. A história de vida de Paulo foi marcada pela incompreensão da sociedade, fazendo construir um caminho de transgressão e luta social. O lugar do sofrimento em sua vida é marcado pela contestação das normas sociais e pela determinação de produzir novos encontros diferentes da regra estabelecida, o que ajuda a construir sua identidade. Mas, é importante destacar que ambas as histórias revelam circunstâncias individuais, familiares ou sociais de abandono ou rejeição que identificam os participantes com um lugar de não pertencimento social, uma condição de não aceitação que produz um sentimento de inadequação e sofrimento de estar com o mundo.

Em certa medida, quando esse conflito é vivido, a pessoa pode perder a capacidade de dar respostas e soluções criativas para as relações conflitantes, se limitando a viver em um jogo de representação social e estereotipia. A relação de estar no mundo supera a relação de estar com o mundo e a pessoa perde a capacidade de regular suas necessidades com as necessidades do grupo social, criando espaços de autoproteção que seguem uma dinâmica rígida para a obtenção de uma aceitação (Perls, 1973/1988).

Para Perls (1973/1988), esse dilema entre agir conforme suas necessidades e a representação social é base para a saúde e maturidade psicológica. Nesse sentido, é válido considerar que o processo de sofrimento nasce também de um comportamento defensivo para a incapacidade da consciência de lidar com 
os sentimentos gerados da condição de não aceitação no mundo: entre eles, a culpa, a mágoa, a raiva e o ódio. O ódio é o que mais afeta Arthur, e está na base de sua relação de violência com os outros e com ele mesmo. A culpa por não ser quem os pais desejaram está na base dos conflitos de Paulo.

Nessa dinâmica, cuidado e autoconhecimento foram aspectos que permitiram mais saúde em oposição aos aspectos rígidos do diagnóstico recebido, ao passo que nem Arthur, nem Paulo sentiram-se contemplados com a definição e proposta de cuidado e saúde da psiquiatria para seus processos de sofrimento. Ambos reconheceram que o bem-estar não é um lugar de plenitude a ser alcançado, mas é antes de tudo um processo de convivência consigo mesmo e com o mundo, em seu exercício cotidiano, em suas vidas e nos percursos de cuidado que escolheram. Esse reconhecimento, de acordo com Perls (1973/1988), é a base de uma relação saudável consigo mesmo e com o mundo.

Os dois disseram que os remédios psiquiátricos não os ajudaram em relação ao sofrimento vivido e ressaltaram que o que obtiveram na relação com a psiquiatria foi à supressão de sintomas em detrimento do autoconhecimento. Isso explica, em parte, o porquê de os participantes buscarem itinerários terapêuticos diferentes do cuidado profissional estabelecido no campo da saúde mental.

Paulo teve um bom encontro com a psicologia como forma de cuidado, depois de adulto. Mas revelou também seu incômodo com o processo terapêutico que viveu na adolescência e que acentuou mais o seu sofrimento. Sobre a psiquiatria, ele define que não precisava de remédios e sim de afirmação. E sobre o contato com a psicologia na adolescência, ele entende que era mais uma forma de opressão para a sexualidade que ele desejava viver. Paulo não se sentiu olhado enquanto pessoa, sendo que todo seu conflito, em sua concepção, foi encoberto pelo diagnóstico de TDH. Arthur, por sua vez, revela um encontro possível com a psiquiatria, apesar das críticas. Para ele, o diagnóstico de depressão infantil o tornou uma pessoa doente, o que gerou mais sofrimento. No entanto, revela que foram os remédios que lhe permitiram minimamente a condição de viver com suas dores e angústias, como uma forma de anestesiar os sentimentos. As histórias revelam um distanciamento das ciências da psicologia e da psiquiatria como possibilidades terapêuticas que se atentam para a pessoa que sofre, denunciando que, em seus encontros com essas disciplinas, não foram vistos como pessoas. O problema ou a doença determinaram o tom da relação, deixando de lado a compreensão da própria pessoa que se encontra em sofrimento.

Para Perls (1973/1988), é no reposicionamento da pessoa diante dos conflitos manifestados, reconhecendo o sofrimento e se permitindo entrar em contato com a natureza relacional do mesmo, que é possível encontrar novas respostas para os conflitos, com mais autonomia e criatividade. Nesse contexto, a transgressão, a rebeldia, a intensidade das ações e o uso de drogas nascem como tentativas de resposta para a condição de cristalização da norma social. Trata-se de uma tentativa de mudança da ordem relacional que provoca um desequilíbrio.

Para Heidegger (1927/2005), o homem reflete a dificuldade de lidar consigo, sendo a doença a manifestação de uma limitação de possibilidade de viver, resultando em perda de liberdade de ser, que no sentido existencial gera o sofrimento. E, se em essência existe essa dificuldade, também em essência o ser humano tem necessidade de ajuda. O uso ritualístico da ayahuasca parece permitir o encontro com novas possibilidades de viver, e, por conseguinte, configura-se como instrumento de transformação ou de cura, como denomina Arthur. Nesse sentido, é importante clarificar que o termo "cura”, utilizado pelos participantes, não se restringe ao sentido biomédico de supressão de uma doença ou conflito, e sim compreendido como a capacidade de incorporar novos sentidos aos conflitos que representam sofrimento, permitindo-se novas possibilidades de viver. Cura, no sentido fenomenológico-existencial proposto por Heidegger (1927/2005), também é cuidado e ontologicamente significa presença e compreensão de si.

Tradicionalmente, no xamanismo indígena a ayahuasca é usada para a compreensão das doenças, sendo incluída no sistema de medicina tradicional de muitas etnias (Luz, 2002; Matos \& Nunes, 2016). No vegetalismo peruano, as plantas ganham a conotação de mestres ou professoras pela sua capacidade de transmitir ensinamentos (Labate, 2011; Mabit, 2007; Mercante, 2017). As religiões focaram mais as propriedades espirituais da bebida, mas nem por isso deixaram de lado a concepção de entender a bebida como um importante processo de compreensão e autoconhecimento (Ricciardi, 2008). Os movimentos independentes e neoayahuasqueiros revestem-se dessa diversidade e compreendem o sentido espiritual e de evolução trazido pela bebida também como curativo (Fernandes, 2018; Labate, 2004). Nessa diversidade de usos e em consonância com as tradições originárias, o uso da bebida sempre se destacou como forma medicinal espiritual, que age de forma misteriosa, permitindo um contato com o sobrenatural. Os relatos de transformação e cura são evidenciados por frequentadores da UDV, Santo Daime, Barquinha, grupos vegetalistas e até tradições neoxamânicas que incorporam práticas de medicina alternativa (Fernandes, 2018; Melo, 2010; Mercante, 2013; Mercante, 2017; Ricciardi, 2008; Rose, 2005).

Para Paulo e Arthur, o processo de transformação é retratado especialmente pela possibilidade de entrar em contato com aspectos desagradáveis da consciência e os ressignificar. O lugar de esclarecimento de si manifestado pela experiência com ayahuasca como uma professora guiando e desvelando os sentimentos desagradáveis a consciência é ressaltada com maior re- 
levância. Além disso, também se referem ao domínio sobrenatural, destacando o papel de cuidado também assumido pelas plantas, que ganham a representação de uma entidade cuidadora da própria natureza. Nos relatos de Paulo e Arthur, é possível identificar uma percepção de acolhida, afeto e amor que essa força abstrata manifestada é capaz de proporcionar às pessoas, enquanto os aspectos difíceis da consciência são experimentados na vivência. Em oposição à ontologia ocidental, no saber praticado nas culturas que utilizam ayahuasca como acesso ao mundo espiritual, existe a concepção de que as plantas e outros elementos da natureza são seres que possuem inteligência e, sendo assim, que se manifestam durante a ritualística (Albuquerque, 2014). A vivência não racional dos participantes é compreendida no processo cultural e espiritual dos grupos, dando suporte para integração da experiência.

Um conceito fundamental em gestalt-terapia é a confiança na pessoa como produtora de significados durante o processo terapêutico (Perls, 1973/1988). No caso da ayahuasca, parece que essa produção de significados acontece a partir da relação de cuidado da pessoa com ela mesma e com as plantas-professoras. A comunidade e a doutrina religiosa tornam-se alicerces no processo que é construído pela pessoa em uma experiência de esclarecimento do ser. Heidegger (1927/2005) define o sentido ontológico de cuidado como a manifestação do esclarecimento do ser. Essa manifestação de conhecimento de si propicia desenvolver relações mais saudáveis no processo de estar com o mundo. A cura, nessa concepção, é a própria revelação do cuidado de si e acontece por meio da clarificação de aspectos antes renunciados pelo ser.

Arthur relata esse processo à medida que diz que viveu uma experiência de aceitação de tudo aquilo que ele havia vivido, mas que não admitia, precisando assim sedimentar seus sentimentos, sem necessariamente conseguir ter autocontrole da raiva e do ódio que havia dentro de si. Paulo ganhou a consciência da culpa e da mágoa que atravessavam suas relações, à medida que não conseguiu ser o filho que seus pais queriam ter ou estabelecer as relações de aceitação de queriam ter com os pais. Tais conflitos só puderam ser colocados em evidência a partir do cuidado e acolhimento que, nesse contexto, é apresentado dentro da própria experiência no ritual.

A cura também é amor, consideram ambos os participantes. O amor, por sua vez, é o alicerce para o cuidado. No percurso de Paulo e Arthur, cuidado e cura significam a possibilidade de amar a si mesmo, possibilitando também maior presença e compreensão do ser, essências da liberdade de existir.

A enfermidade explica algo sobre o momento de vida e sobre o medo de perder a liberdade de ser, a partir das relações desenvolvidas no mundo (Heidegger, 1927/2005). A cura é experimentada à medida que as sensações dolorosas e ameaçadoras de estar no mundo dão lugar a respostas mais criativas e espon- tâneas aos problemas, permitindo também mais autonomia. Nesse aspecto, os participantes trazem em sua narrativa uma capacidade para irem em direção à liberdade e assimilar novos mecanismos de autorregulação com o mundo, a partir de uma sabedoria já existente dentro de si. Dessa forma, demostram que bem-estar é acreditar, aceitar e amar a si próprio.

As pesquisas têm destacado a propensão das pessoas que participam de grupos ayahuasqueiros de desenvolverem bem-estar mental. Ainda, é crescente o interesse em experimentos com ayahuasca para tratar depressão, trauma e dependência de drogas. (Assis, 2016; Bouso \& Riba, 2014; Dias de Jesus Júnior, de Oliveira Salvi, \& Ramos Evangelista, 2015; Doering-Silveira et al., 2005; Escobar, 2012; Grob et al., 2004; Halpern et al., 2008; Lizardo de Assis, Faria \& Lins, 2014; Mercante, 2013; Mercante, 2017; Mckenna, 2004; Osório, 2011; Osório et al., 2015; Palhano-Fontes et al., 2013; Palhano-Fontes et al., 2019; Silveira et al., 2005).

Na perspectiva desta pesquisa, é inegável que o processo descrito pelos participantes remete a memórias e lembranças que os fizeram capazes de compreender os sentimentos associados ao sofrimento e às enfermidades. A forma como o cuidado acontece durante a prática ritualística é que não tem relação com o tipo de cuidado biomédico. Trata-se de um processo corporal, mental, cultural e espiritual, vivenciado concomitantemente. $\mathrm{O}$ destaque evidenciado no processo de cura é a mudança de postura diante do sofrimento, e das lembranças e memórias que fazem sofrer. Sem desconsiderar a atuação neuroquímica das substâncias no organismo, o efeito de conscientização de aspectos desagradáveis e renunciados pelo ser, aliado ao cuidado e acolhimento comunitário, parece ser essencial. O processo de cuidado que ocorre durante a ritualística não pode ser definido por meio da propriedade de suas substâncias para deletar as lembranças traumáticas, ou provocar estados de bem-estar explícito sem reflexão consciente. O cuidado descrito pelos participantes é evidenciado como um percurso terapêutico vivencial de tomada de consciência e emergência de novos comportamentos e atitudes a partir da autorreflexão, e não como forma de apagar o sofrimento da vida.

\section{Conclusão}

Uso ritualístico da ayahuasca, saúde e espiritualidade: o lugar da terapêutica

O objetivo principal desse estudo foi à compreensão de sentidos conferidos à ayahuasca na construção de percursos terapêuticos ligados ao uso ritualístico da bebida por usuários que apresentam ou apresentaram processos de sofrimento. Foram evidenciadas seis unidades significativas de análise que caracterizaram abrangência de sentidos captada pelos 
participantes dentro dos seus percursos com a prática ritualística.

O reconhecimento do sofrimento e a busca pelo bem-estar compreenderam sentidos que evidenciaram os processos e motivações para frequentar o uso ritual de ayahuasca. O encontro com as drogas evidencia situações importantes que refletem situações associadas ao sofrimento. O encontro com ayahuasca, em oposição à relação vivida com as drogas, é identificado como um instrumento de cuidado e conhecimento de si, sendo referenciado como uma possibilidade terapêutica de encontro consigo mesmo.

Desta maneira, a ressignificação de sentidos é integrada a partir da disponibilidade à mudança após experiência ritual com a bebida. Essas transformações são associadas, especialmente, a enfermidades relacionadas à saúde mental, ao uso de drogas e às relações interpessoais. O encontro com o sagrado revela o sentido sublime atribuído a essa terapêutica, que é experimentada a partir de uma relação de temor e admiração com uma força abstrata, não racional, que se manifesta como cuidadora e professora no conhecimento de si. Essa força é significada como a própria manifestação da natureza divina e permite, sobretudo, as expressões de perdão, compaixão, amor e gratidão.

As histórias de vida contemplaram aspectos importantes que abarcam as experiências de sofrimento que se manifestam na vida, e sobre como é possível cuidar e entender melhor a dinâmica de sofrer, sendo possível, a partir disso, projetar também uma melhor qualidade de vida. No sentido fenomenológico, a experiência do uso ritualístico da ayahuasca representou um fortalecimento na relação dos participantes com o mundo, permitindo maior autorregulação e confiança em si mesmo. Esse papel, dentro da perspectiva das escolas humanistas de psicoterapia, equivale ao papel do terapeuta.

A relação entre a experiência com ayahuasca e os percursos nomeados como terapêuticos na trajetória de vida foi identificada por meio dos cuidados e ensinamentos que ajudaram a ressignificar atitudes e assumir novas posturas que equivalem a uma melhor qualidade de vida. Dentre as práticas terapêuticas nos rituais, são destacadas as visões, as limpezas e a clarificação mental conduzida por meio de uma força não racional que é acolhedora, cuidadora e também professora da consciência. O acolhimento e os ensinamentos da comunidade também são identificados como importantes no processo de cuidado, mas com ressalvas sobre a doutrina religiosa e comportamento moral dos grupos. Ressalta-se o papel de cuidado e ensino atribuídos à manifestação divina da natureza como parte de tecnologias de saúde já existentes em conhecimentos tradicionais e populares de saúde.

Dos elementos da experiência identificados como importantes, a relação com essa força divina tem papel fundamental, tanto no desvelamento de processos responsáveis pelo sofrimento, quanto por permitir o senti- mento de transcendência que denota a certeza de fazer parte, permitindo assim mais confiança e amor em si mesmo. Dessa integração de sentidos nasce a disposição à mudança: a percepção do egoísmo e a disposição de assumir relações mais empáticas; o reconhecimento dos ressentimentos e a atitude do perdão; a percepção da raiva e do ódio e a identificação de compaixão e amor; a percepção da enfermidade e a motivação para assumir hábitos mais saudáveis. Nasce, ainda, gratidão e valorização da vida com o sentimento de fazer parte da criação. Nesse sentido, a gratidão à vida se opõe a aspectos destrutivos do ser, permitindo maior equilíbrio e bem-estar.

Além disso, os participantes significaram bem-estar, não como um lugar de plenitude a ser alcançado, mas antes de tudo um processo de convivência consigo mesmo e com o mundo, em seu exercício cotidiano, em suas vidas e nos percursos de cuidado que escolheram: o que puderam e podem fazer é encontrar formas equilibradas de lidar com o sofrimento, o que nem sempre é possível. E, nesse sentido, o cuidado faz parte da vida, também como um processo diário de se amar e assumir hábitos saudáveis.

Em resumo, o estudo identificou que enquanto tecnologia de saúde, a ayahuasca é definida pelos participantes a partir das visões, das limpezas e da clarificação mental trazida pela manifestação de uma força sagrada, além do suporte grupal que permite cuidado e continência. A falta de delimitação do campo ritualístico, assim como a dificuldade de acesso aos participantes que fizeram uso ritualístico da bebida, mas que não são frequentadores das religiões, foram aspectos limitantes do campo de pesquisa.

Refletimos que a racionalidade científica não pode determinar essas práticas como mágicas, supersticiosas ou mesmo como um ato de fé, apenas porque não compreendem uma equação que permite a comparabilidade com o método científico. Nas tradições originárias e encontros com novas tradições, a diversidade ayahuasqueira hoje, desenvolve suas próprias concepções sobre saúde e doença e suas próprias tecnologias de saúde. Considerando o aspecto ontológico envolvido na trama de sentidos e possibilidades que se revelam nas práticas ritualísticas com ayahuasca na atualidade, torna-se necessário um posicionamento dos estudos científicos sobre as possibilidades terapêuticas da ayahuasca.

Por fim, ressaltamos a importância da compreensão fenomenológica dos processos de saúde e doença, que permite a descrição dos processos de sofrimento e caminhos de cuidado que se fazem significativos por meio da experiência vivida pelos participantes. Dessa forma, entendemos que a relevância deste estudo está na contribuição dada pelas experiências de vida dos participantes que nos faz entender que o campo de definição e cuidado de saúde mental, álcool e outras drogas é percorrido por múltiplos significados que não podem ser reduzidos a caraterísticas das doenças e padrões de tratamento. Futuras pesquisas devem 
se ocupar da discussão ontológica necessária para o campo de estudo que pretende refletir e discutir a possibilidade do uso terapêutico da ayahuasca.

\section{Referências}

Assis, J. T. (2016). Uso ritualístico da ayahuasca: percursos terapêuticos, saúde e espiritualidade. (Unpublished doctoral dissertation). Universidade de Brasília, Brasília.

Assis, J. T., Barreiros, G. B., \& Conceição, M. I. G. (2013). A internação para usuários de drogas: diálogos com a reforma psiquiátrica. Revista Latino-Americana de Psicopatologia Fundamental, 16(4), 584-596.

Albuquerque, M. B. A. (2014). Epistemologia da ayahuasca e a dissolução das fronteiras natureza/cultura da ciência moderna. Fragmentos de Cultura, 24(2), 179-193.

Bouso, J. C., \& Riba, J. (2014). Ayahuasca and the treatment of drug addiction. In B. C. Labate \& C. Cavnar (Eds.), The therapeutic use of ayahuasca (pp. 95-109). Springer-Verlang: Berlin Heidelberg.

Bucher, R. (1996). Drogas e Sociedade nos Tempos de AIDS. Brasília: UnB.

Critelli, D. (2012). História Pessoal e Sentido da VidaHistoriobiografia. São Paulo: EDUC.

Dias de Jesus Júnior, T., de Oliveira Salvi, J., \& Ramos Evangelista, D. H. (2015). Ayahuasca, qualidade de vida e a esperança de adictos em recuperação: relatos de caso. Acta toxicológica argentina, 23(1), 53-61.

Doering-Silveira, E., Lopez, E., Grob , C. S., Dobkin de Rios, M., Alonso, L. K., Tacla, C., Bertolucci, P. H., \& Da Silveira, D. X. (2005). Ayahuasca in adolescence: A neuropsychological assessment. Journal of Psychoactive Drugs, 37(2), 123-128.

Escobar, J. A. C. (2012). Ayahuasca e Saúde: Efeitos de uma Bebida Sacramental Psicoativa na Saúde Mental de Religiosos Ayahuasqueiros (Unpublished doctoral dissertation). Universidade Federal de Pernambuco, Recife.

Fernandes, S. C. (2018). Xamanismo e neoxamanismo no circuito do consumo ritual das medicinas da floresta. Horizontes Antropológicos, 24(51), 289314.

Gaulejac, V. de (2014). Opções e suportes metodológicos. In V. de Gaulejac (Ed.), A neurose de classe: trajetória social e conflitos de identidade (pp. 167-181). São Paulo: Via Lettera.
Grob, C. S., McKenna, D. J., Callaway, J. C., Brito, G. S., Neves, E.S., Oberlaender, G., Boone, K. S. (2004). Farmacologia humana da hoasca: efeitos psicológicos. In B. C. Labate, B.C. \& W.S. Araújo (Eds.), O uso ritual da ayahuasca (pp. 653-669). Campinas: Mercado de Letras.

Halpern, J. H., Sherwood, A. R., Passie, T., Blackwell, K., \& Ruttenber A. J. (2008). Evidence of health and safety in American members of a religion who use a hallucinogenic sacrament. Medical Science Monitor, 14(8), 15-22.

Heidegger, M. (2005). Ser e Tempo. Rio de Janeiro: Vozes, 2005. (Trabalho original em 1927)

Labate, B. C. (2004). A reinvenção do uso da ayahuasca nos centros urbanos. Campinas, São Paulo: Mercado das Letras.

Labate, B C. (2011). Ayahuasca Mamancuna merci beaucoup: internacionalização e diversificação do vegetalismo ayahuasqueiro peruano (Unpublished doctoral dissertation). Universidade de Campinas, Campinas.

Lizardo de Assis, C., Faria, D. F., \& Lins, L. F. T. (2014). Bem-estar subjetivo e qualidade de vida em adeptos de ayahuasca. Psicologia \& Sociedade, 26(1), 224-234.

Luz, P. F. L. (2002). O uso ameríndio do caapi. In B. C. Labate \& W. S. Araújo (Eds.), O uso ritual da ayahuasca (pp. 37-68). Campinas, São Paulo: Mercado de Letras.

Mabit, J. (2007). Ayahuasca in the treatment of addictions. In J.M. Winkelman \& T. B. Roberts (Eds.), Psychedelic Medicine: new evidence for hallucinogenic substances as treatments (pp. 87-105). Westport: Praeger.

Matos, M. B. M. \& Nunes, M. da S. (2016). Medicina tradicional: terapia indígena no estado do Acre. Journal of Amazon Health Science, 2(1). Retrieved from: http://revistas.ufac.br/revista/index.php/ahs/article/view/333

Mckenna, D. J., Callaway J. C., \& Grob, C. S. (1998). The Scientific Investigation of ayahuasca: A Review of Past and Current Research. The Heffter Review of Psychedelic Research, 1, 65-67.

McKenna, D. J. (2004). Clinical investigations of the therapeutic potential of ayahuasca: rationale and regulatory challenges. Pharmacology \& Therapeutics, 102(2), 111-129.

Melo, R. V. de A. (2010). Beber na fonte: adesão e transformação na União do Vegetal (Unpublished doctoral dissertation). Universidade de Brasília, Brasília. 
Mercante, M. (2013). A ayahuasca e o tratamento da dependência. Mana, 19(3), 529-558.

Mercante, M. (2017). Imaginação, linguagem, espíritos e agência: ayahuasca e o tratamento da dependência química. Revista de Antropologia (São Paulo, Online), 60(2), 562-587.

Olivenstein, C. (1989). A clínica do toxicômano. Porto Alegre: Artes Médicas.

Osório, F. L., Macedo, L. R. H., Souza, J. P., Pinto, J. P., Quevedo, J., Crippa, J., \& Hallak, J. E. C. (2011). The therapeutic potencial of harmine and ayahuasca in depression: evidence from exploratory animal e human studies. In R. G. Santos (Ed.), The Ethenopharmacology of Ayahusca (pp. 7589). Kerala: India.

Osório, F. L., Sanches, R. F., Macedo, R. L. H., Santos, R. G., Maia-de-Oliveira, J. P., Wichert, A., Hallak, J. E. (2015). Antidepressant effects of a single dose of ayahuasca in patients with recurrent depression: a preliminary report. Revista Brasileira de Psiquiatria, 37(1), 13-20.

Palhano-Fontes, F., Alchieri, J. C., Oliveira, J. P. M., Soares, B. L., Hallak, J. E. C., Galvao-Coelho, N., \& Araujo, D, B. (2014). The Therapeutic Potentials of Ayahuasca in the Treatment of Depression. In B. C. Labate \& C. Cavnar (Eds.), The Therapeutic Use of Ayahuasca (pp. 23-39). Springer-Verlang: Berlin Heidelberg.

Palhano-Fontes, F, Barreto, D, Onias, H, Andrade, K.C., Novaes, M.M., Pessoa, J.A., Mota-Rolim, S.A., Osório, F.L., Sanches, R., Dos Santos, R.G., Tófoli, L.F., de Oliveira Silveira, G., Yonamine, M., Riba, J., Santos, F.R., Silva-Junior, A.A., Alchieri, J.C., Galvão-Coelho, N. L., Lobão-Soares, B., Hallak, J.E.C., Arcoverde, E., Maia-de-Oliveira, J.P., Araújo, D.B.. (2019) Rapid antidepressant effects of the psychedelic ayahuasca in treatment-resistant depression: a randomized placebo-controlled trial. Psychol Med, 49(4), 655-663.

Perls, F. (1988). A abordagem gestáltica e testemunha ocular da terapia. Rio de Janeiro: Zahar Editores. (Trabalho original publicado em 1973)

Ricciardi, G. S. (2008). O uso da Ayahuasca e a experiência de transformação, alívio e cura, na União do Vegetal (UDV) (Unpublished master's thesis). Universidade Federal da Bahia Salvador.

Rose, I. S. (2005). Espiritualidade, Terapia e Cura: um estudo sobre a expressão da experiência no Santo Daime (Unpublished master's thesis). Universidade Federal de Santa Catarina, Santa Catarina.
Silveira, D. X., Grob C. S., Marlene Rios, D., Lopez, E., Alonso L. K., Tacla, C., \& Doering-Silveira, E. (2005). Ayahuasca in adolescence: a preliminary psychiatric assessment. Journal Psychoactive Drugs, 37(2), 129-133.

Jaqueline Tavares de Assis (https://orcid.org/00000003-1737-5936), possui graduação em Psicologia pela Universidade de Brasília, mestrado em Processos de Desenvolvimento Humano e Saúde pela Universidade de Brasília e doutorado em Psicologia Clínica e Cultura pela Universidade de Brasília. Atualmente é professora e coordenadora no curso de Psicologia das Faculdades Integradas da União Educacional do Planalto Central. Email: jaqueassis@gmail.com

Maria Inês Gandolfo Conceição (https://orcid. org/0000-0002-4052-33813) é Graduada em Psicologia peloCentro deEnsino Unificado deBrasília, especialista em Psicologia Hospitalar (CRP), mestre em Psicologia pela Universidade de Brasília, doutora em Psicologia pela Universidade de Brasília. Professora Associada IV do Instituto de Psicologia da Universidade de Brasília, onde atua nos cursos de graduação e pós-graduação. Email: inesgandolfo@gmail.com

Recebido em 30.10.2018 Primeira Decisão Editorial em 18.02.2019 Aceito em 02.05.2019 